\title{
A Case of Behcet's Disease with Radiation Proctitis Improved by Oral Administration of Irsogladine
}

\author{
Yutaka Yamaji ${ }^{1 *}$, Yoshihiro Isomura ${ }^{1}$, Shuntaro Yoshida ${ }^{1}$, Atsuo Yamada ${ }^{1}$, Yoshihiro Hirata ${ }^{1}$, Kenshiro Shiraishi ${ }^{2}$, Jinpei \\ Kumagai $^{3}$, Yutaka Enomoto ${ }^{3}$, Yukio Homma ${ }^{3}$ and Kazuhiko Koike ${ }^{1}$ \\ ${ }^{1}$ Department of Gastroenterology, Graduate School of Medicine, The University of Tokyo, Tokyo, Japan \\ ${ }^{2}$ Department of Radiology, Graduate School of Medicine, The University of Tokyo, Tokyo, Japan \\ ${ }^{3}$ Department of Urology, Graduate School of Medicine, The University of Tokyo, Tokyo, Japan
}

Received: June 24, 2014; Accepted: August 26, 2014; Published: September 05, 2014

*Corresponding author: Yutaka Yamaji, Department of Gastroenterology, Graduate School of Medicine, The University of Tokyo, 7-3-1 Hongo, Bunkyoku, Tokyo 113-8655, Japan, Tel: +81-3-3815-5411; Fax: +81-3-3814-0021. E-mail: yamaji-tky@umin.ac.jp

\begin{abstract}
Irsogladine maleate is a gastro-protective drug that is known to increase mucosal blood flow and facilitate gap junctional intracellular communication, leading to fortification of the tight junctions of the entire gastro-intestinal mucosa. Animal experiments have revealed effects in improving radiation-induced intestinal injuries. Clinical efficacy in stomatitis or enteropathy has also been reported. A 76-year-old male with Behcet's disease had been diagnosed with prostate cancer when he was 72 years old, and was treated with a combination of hormone and radiation therapy (50.4 Gy in 28 fractions to the small pelvic region plus a 14.4-Gy boost in 8 fractions to the prostate and seminal vesicles). Beginning 3 months after completion of the radiation treatment, rectal bleeding began and he was diagnosed with radiation proctitis. The bleeding gradually became severe, and 2 year's post-radiation therapy, his hemoglobin level could be maintained at only $\sim 8 \mathrm{~g} / \mathrm{dL}$ even with vigorous iron supplementation. Endoscopic findings also worsened, to more diffuse friability and telangiectasia, classified as Sherman's grade Ib. Once irsogladine was administered, the bleeding promptly began to decrease, and his hemoglobin could be maintained above $10 \mathrm{~g} / \mathrm{dL} 4$ months later. Iron supplementation was discontinued after 1 year. Endoscopic vascular findings and friability improved correspondingly. Thus, we report a case of Behcet's disease with radiation proctitis improved markedly by oral administration of irsogladine maleate.
\end{abstract}

Keywords: Proctitis; Radiation injuries; Anti-ulcer agents; Gastrointestinal hemorrhage; Behcet syndrome

\section{Introduction}

Radiation proctitis occurs chronically in $5-20 \%$ of patients following pelvic radiotherapy for malignancies of the prostate, rectum, urinary bladder, cervix, uterus, and testes [1,2]. Although most patients with acute radiation proctitis have spontaneous remission, the chronic form of this condition is difficult to manage [3]. Some patients have chronic symptoms, including diarrhea, tenesmus, urgency, and rectal bleeding. Approximately 6-8\% of patients with chronic radiation injury suffer persistent rectal bleeding with iron-deficiency anemia, sometimes requiring blood transfusions [4,5].
Treatments for radiation proctitis remain unsatisfactory and the evidence for various therapies has been insufficient [2]. Medical treatments, including topical sucralfate, 5-amino salicylic acid, and corticosteroids, have been used with limited success $[2,6,7]$. Although topical formalin application has been administered with better results, considerable complications have also been reported [8]. Endoscopic therapy using a heater probe, bipolar electrocoagulation, and a neodymium: yttriumaluminium-garnet (Nd:YAG) laser has been reported to be of some benefit, but at the expense of a high rate of complications [2]. Argon Plasma Coagulation (APC) is considered the preferred endoscopic therapy because of its efficacy and safety profile $[2,6,7]$. However, even APC has some complications (19-47\%) $[9,10]$ and repeated therapy is needed for refractory or recurrent lesions [2]. Hyperbaric oxygen therapy is another option, but the equipment is expensive and not readily available [11]. Surgery is associated with high morbidity rates in patients with previous radiation therapy and is therefore usually avoided $[2,6]$.

Irsogladine maleate was originally a gastro-protective drug [12]. It facilitates gap junctional intracellular communication and can strengthen the union of tight junctions in the gastrointestinal mucosa $[12,13]$. The mechanism suggests that this drug could protect the mucosa throughout the gastrointestinal tract $[14,15]$. Effects on stomatitis [15-17], gastric ulcers [18,19], and NSAIDinduced small intestinal injuries[20-23] have been reported. Additionally, animal experiments have suggested favorable effects on post-radiation intestinal injuries [24].

We experienced a case of radiation proctitis improved by oral administration of irsogladine maleate in a patient with Behcet's disease. This case suggests the efficacy of irsogladine in gastrointestinal diseases due to radiation and/or Behcet's disease.

\section{Case Report}

A 76-year-old male was diagnosed with Behcet's disease because he suffered from uveitis, erythema nodosum, and 
aphthous stomatitis when he was 38 years old. He was treated with colchicine, corticosteroids, ticlopidine, and prostaglandin derivatives. He was also diagnosed with a gastric ulcer when he was 54 years old, and treated with an $\mathrm{H}_{2}$ receptor antagonist and sucralfate. Beginning when he was 70 years old, he suffered repeated bleeding from multiple ileal ulcers, which was relieved by mesalamine and cessation of an anti-platelet agent. When he was 72 years old, he was diagnosed with prostate cancer and treated with a combination of hormone and radiation therapy (50.4 Gy in 28 fractions to the small pelvic region plus a14.4-Gy boost in 8 fractions to the prostate and seminal vesicles). At that time his Behcet's disease and gastrointestinal ulcers had been well controlled on colchicine $0.5 \mathrm{mg}$, sucralfate $2.7 \mathrm{~g}$, rebamipide $200 \mathrm{mg}$, roxatidine $150 \mathrm{mg}$, and mesalamine $2250 \mathrm{mg} /$ day.

Beginning 3 months after completing his radiation therapy, rectal bleeding began. No recurrence of the ileal ulcers was found and he was diagnosed with radiation proctitis via colonoscopy. He was given only anti-constipation treatment for several months because the bleeding was mild. However, the bleeding gradually became severe, and he needed increasing doses of iron supplementation accompanied by Vitamin $\mathrm{C}$ to facilitate iron absorption. At 18 months post-radiation therapy, pretibial edema appeared and a diuretic was started. At 2 years post-radiation therapy, his hemoglobin level could be maintained at only $\sim 8 \mathrm{~g} /$ $\mathrm{dL}$ even with vigorous iron supplementation, and increasing the dose of mesalamine from 2,250 to $3,000 \mathrm{mg}$ /day was ineffective (Figure 1). The endoscopic findings also worsened, and showed more diffuse friability and telangiectasia, which was classified as Sherman's grade Ib (Figure 2-A). Throughout this, his Behcet's disease (uveitis, erythema nodosum, and aphthous stomatitis) had been well controlled continuously, and endoscopy again found no recurrence of ileal ulcers.

Argon Plasma Coagulation (APC) therapy had been reserved as possible. Because the area of bleeding was diffuse in the rectum, many sessions of APC would be needed, and because he had Behcet's disease, the ulcer after APC might be severe and the

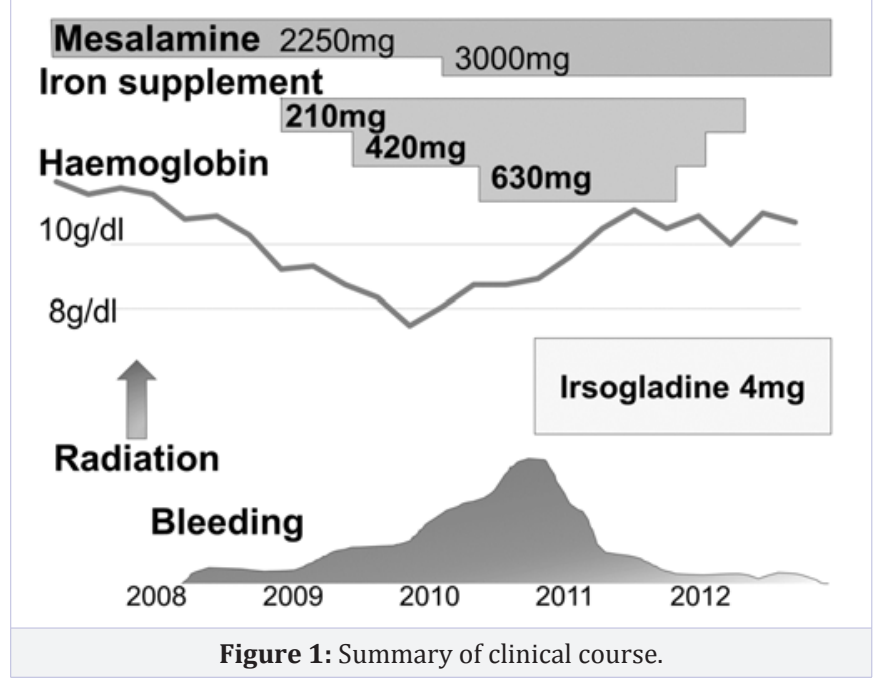

mucosal repair delayed. As the bleeding became more severe, APC therapy was planned. However, before that, administration of irsogladine maleate was tried. The other drugs concurrently used were mesalamine $3,000 \mathrm{mg}$, iron supplementation (administered as ferrous sulphate hydrate) $630 \mathrm{mg}$, colchicine $0.5 \mathrm{mg}$, sucralfate $2.7 \mathrm{~g}$, rebamipide $200 \mathrm{mg}$, roxatidine $150 \mathrm{mg}$, magnesium oxide $0.5 \mathrm{~g}$, indapamide $1 \mathrm{mg}$, and combination granule of ascorbic acid (600 $\mathrm{mg}$ ) and calcium pantothenate $(9 \mathrm{mg}$ ), all of which were administered orally daily. The bleeding began to clearly decrease within 1 month, and his hemoglobin could be maintained above $10 \mathrm{~g} / \mathrm{dL} 4$ months later. Iron supplementation was reduced and discontinued after 1 year (Figure 1). Endoscopic vascular findings and friability also improved, to grade Ia (Figure 2-B). To be continued.

\section{Discussion}

We report a case of radiation proctitis improved by oral administration of irsogladine maleate. This is the first case report in which irsogladine showed a clinical effect on a radiationinduced intestinal disorder.

Irsogladine (2,4-diamino-6-[2,5-dichlorophenyl]-s-triazine maleate) was developed in Japan for the treatment of peptic ulcers and acute gastritis [12]. Irsogladine increases the intracellular cyclic adenosine 3',5'-monophosphate (cAMP) content via nonselective inhibition of phosphodiesterase (PDE) isozymes and exhibits gastric cytoprotection, partly mediated by endogenous nitric oxide [25]. Based on these activities, various actions of irsogladine in the gastrointestinal tract are known, including the facilitation of Gap Junctional Intracellular Communication (GJIC) [13], inhibition of the reduced gastric mucosal blood flow response [26], and suppression of reactive oxygen species generation [27]. Among these properties, the facilitation of GJIC is considered the most important and unique function of irsogladine. Several studies have suggested that connexins, in gap junction induce and maintain tight junctions $[28,29]$ and it has been reported that irsogladine suppressed mucosal permeability via the up-regulation of claudin-4, a component of tight junctions [30]. Since connexins, the target of irsogladine, are distributed along the entire digestive tract, irsogladine might potentially act throughout the digestive tract $[12,15]$. As irsogladine is absorbed into the small intestine and acts on mucosal cells from the vessel side, it has the potential to affect the entire gastro-intestinal tract irrespectively of the luminal $\mathrm{pH}$. Moreover, it might have a greater effect on enteropathy that is independent of the strong actions of gastric acid [12,20,31].

These effects on the mucosal barrier might be especially appropriate for intestinal damage induced by NSAIDs, because the major mechanism of intestinal mucosal injuries apart from gastric acid has been assumed to be disruption of intercellular junctions, due to mitochondrial damage by NSAIDs [32,33]. In fact, protective effects of irsogladine on indomethacin-induced small intestinal lesions have been demonstrated in an experimental rat model [20]. We and others have reported the effects of irsogladine 

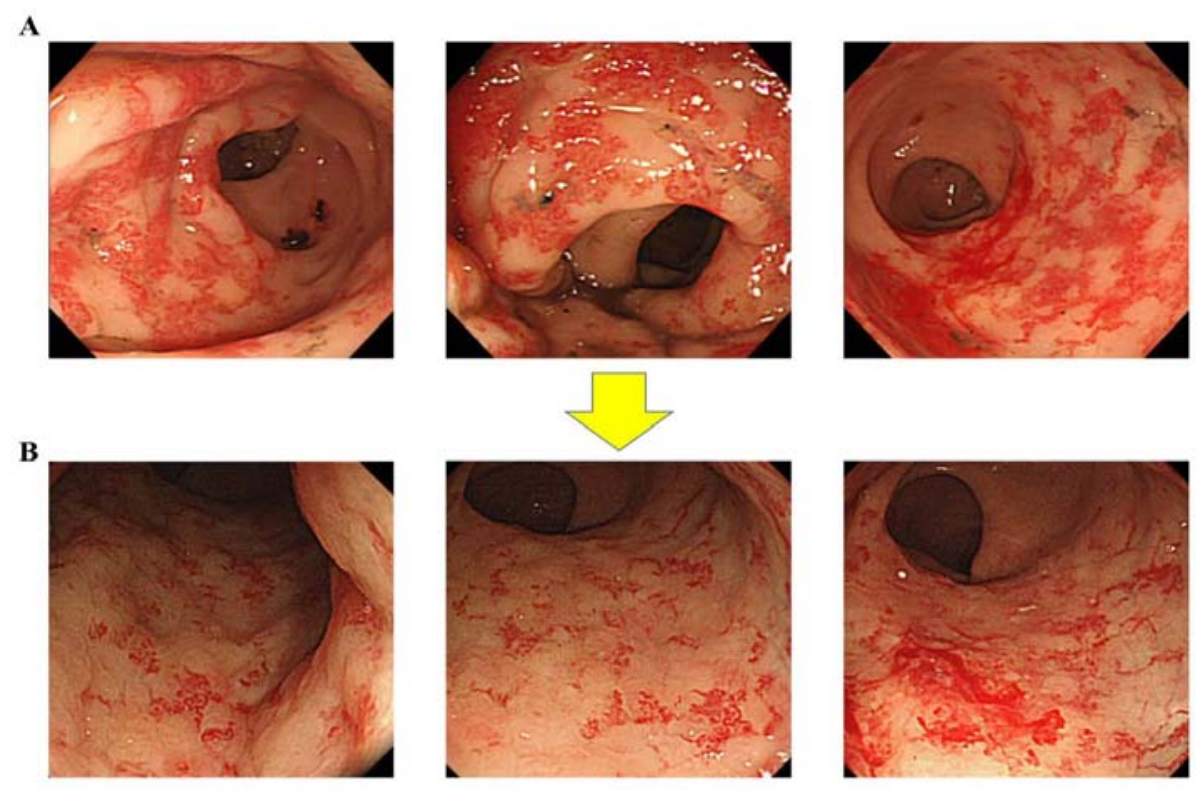

Figure 2: Improvement in endoscopic vascular findings and friability.

A. Before treatment;

B. After treatment of Irsogladine.

in humans on NSAID-induced injuries in the small bowel [21-23]. Effects of irsogladine in stomatitis due to Behcet's disease [16] or anti-cancer drugs [17] have also been reported. Irsogladine has potential for the treating various intestinal mucosal injuries.

The etiology of hemorrhagic radiation proctitis is considered to be chronic mucosal ischemia, caused by tissue fibrosis and obliterative endarteritis, leading to the development of neovascular lesions [34]. The mechanism of the effect of irsogladine in the present case is unclear. However, the effects of facilitating GJIC, increasing mucosal blood flow, and suppressing of reactive oxygen species generation are assumed to be involved in repair of radiation-induced intestinal damage $[12,24]$

We attempted irsogladine treatment in another patient with liver cirrhosis presenting with life-threatening bleeding due to radiation gastroduodenopathy. Bleeding was intensified by coagulopathy due to the liver cirrhosis. Although APC controlled the bleeding during a short period, the ulcer produced by APC became refractory and exacerbated the illness. In this case, irsogladine showed no demonstrable effect. The primary reason for the lack of effectiveness was thought to be the severity of the bleeding which required emergency hospitalization. In our case, the Behcet's disease might have modified the clinical manifestations. Bleeding might have been more severe, partly due to the mucosal impairment in Behcet's disease. Irsogladine could be also effective on friability due to Behcet's disease, given that recent reports have suggested effects of irsogladine on stomatitis in Behcet's disease [16]. A histopathological investigation might have been of more diagnostic value in this case. However, we were afraid that a biopsy would cause more bleeding and refractory ulceration. Since his Behcet's disease had been well controlled, and the timing, location, and endoscopic findings were all compatible with radiation proctitis, we diagnosed it without performing a biopsy.

This case suggests that irsogladine is a candidate lessinvasive medical treatment of radiation proctitis. Cases should be accumulated to generalize this assessment and the mechanism should be examined in future studies.

\section{References}

1. Gilinsky NH, Burns DG, Barbezat GO, Levin W, Myers HS, Marks IN. The natural history of radiation-induced proctosigmoiditis: an analysis of 88 patients. Q J Med. 1983; 52(205): 40-53.

2. Rustagi T, Mashimo H. Endoscopic management of chronic radiation proctitis. World J Gastroenterol. 2011; 17(41): 4554-62. doi: 10.3748/ wjg.v17.i41.4554.

3. Babb RR. Radiation proctitis: a review. Am J Gastroenterol. 1996; 91(7): 1309-11.

4. Buchi KN, Dixon JA. Argon laser treatment of hemorrhagic radiation proctitis. Gastrointest Endosc. 1987; 33(1): 27-30.

5. Silva RA, Correia AJ, Dias LM, Viana HL, Viana RL. Argon plasma coagulation therapy for hemorrhagic radiation proctosigmoiditis. Gastrointest Endosc. 1999; 50(2): 221-4.

6. Wilson SA, Rex DK. Endoscopic treatment of chronic radiation proctopathy. Curr Opin Gastroenterol. 2006; 22(5): 536-40.

7. Takemoto S, Shibamoto Y, Ayakawa S, Nagai A, Hayashi A, Ogino H, et al. Treatment and prognosis of patients with late rectal bleeding after intensity-modulated radiation therapy for prostate cancer. Radiat Oncol. 2012; 7: 87. doi: 10.1186/1748-717X-7-87.

8. Sahakitrungruang C, Patiwongpaisarn A, Kanjanasilp P, Malakorn $S$, Atittharnsakul P. A randomized controlled trial comparing 
colonic irrigation and oral antibiotics administration versus $4 \%$ formalin application for treatment of hemorrhagic radiation proctitis. Dis Colon Rectum. 2012; 55(10): 1053-8. doi: 10.1097/ DCR.0b013e318265720a.

9. Canard JM, Vedrenne B, Bors G, Claude P, Bader R, Sondag D. Long term results of treatment of hemorrhagic radiation proctitis by argon plasma coagulation. Gastroenterol Clin Biol. 2003; 27(5): 455-9.

10.Villavicencio RT, Rex DK, Rahmani E. Efficacy and complications of argon plasma coagulation for hematochezia related to radiation proctopathy. Gastrointest Endosc. 2002; 55(1): 70-4.

11. Girnius S, Cersonsky N, Gesell L, Cico S, Barrett W. Treatment of refractory radiation-induced hemorrhagic proctitis with hyperbaric oxygen therapy. Am J Clin Oncol. 2006; 29(6): 588-92.

12. Akagi M, Amagase K, Murakami T, Takeuchi K. Irsogladine: overview of the mechanisms of mucosal protective and healing- promoting actions in the gastrointestinal tract. Curr Pharm Des. 2013; 19(1): 106-14.

13. Kameda Y, Ueda F. Irsogladine inhibits ionomycin-induced decrease in intercellular communication in cultured rabbit gastric epithelial cells. Jpn J Pharmacol. 1995; 69(3): 223-8.

14. Ando T, Momota K, Sugiyama M. Absorption, distribution and excretion of 2,4-diamino-6-(2,5-dichlorophenyl)-s-triazine maleate in rats, dogs and monkeys. Arzneimittelforschung. 1986; 36(8): 1221-8.

15. Hara A, Murata T, Uemura R, Miura T, Fukui K, Matsukawa H, et al Identification of connexins in human oral mucosa and therapeutic effect of irsogladine maleate on aphthous stomatitis. J Gastroenterol. 1999; 34(1): 1-6.

16. Nanke Y, Kamatani N, Okamoto T, Ogiuchi H, Kotake S. Irsogladine is effective for recurrent oral ulcers in patients with Behcet's disease : an open-label, single-centre study. Drugs R D. 2008; 9(6): 455-9. doi: 10.2165/0126839-200809060-00008.

17. Nomura M, Kamata M, Kojima H, Hayashi K, Sawada S. Irsogladine maleate reduces the incidence of fluorouracil-based chemotherapyinduced oral mucositis. Ann Oncol. 2013; 24(4): 1062-6. doi: 10.1093/ annonc/mds584.

18. Hiraishi H, Haruma K, Miwa H, Goto H. Clinical trial: irsogladine maleate, a mucosal protective drug, accelerates gastric ulcer healing after treatment for eradication of Helicobacter pylori infection-the results of a multicentre, double-blind, randomized clinical trial (IMPACT study). Aliment Pharmacol Ther. 2010; 31(8): 824-33. doi: 10.1111/j.1365-2036.2010.04250.x.

19. Murakami K, Okimoto T, Kodama M, Tanahashi J, Mizukami $\mathrm{K}$, Shuto $\mathrm{M}$, et al. Comparison of the efficacy of irsogladine maleate and famotidine for the healing of gastric ulcers after Helicobacter pylori eradication therapy: a randomized, controlled, prospective study. Scand J Gastroenterol. 2011; 46(3): 287-92. doi: 10.3109/00365521.2010.531485.

20. Kamei K, Kubo Y, Kato N, Hatazawa R, Amagase K, Takeuchi K. Prophylactic effect of irsogladine maleate against indomethacininduced small intestinal lesions in rats. Dig Dis Sci. 2008; 53(10): 2657-66. doi: 10.1007/s10620-008-0199-9.

21. Kuramoto T, Umegaki E, Nouda S, Narabayashi K, Inoue T, Takii
M, et al. Small Intestinal Mucosal Adaptation in the Long-Term Administration of a NSAID and the Efficacy of Irsogladine Maleate, a Gastroprotective Drug, and Omeprazole in Healthy Volunteers: A Prospective Randomized Trial. Gastrointest Endosc. 2012; 75 (Suppl): 257.

22. Nishimura N, Yamamoto H, Shinhata $\mathrm{H}$, et al. Effects of irsogladine maleate on NSAID-induced small bowel injury: a prospective, randomized, crossover, placebo-controlled trial with evaluation by capsule endoscopy. J Gastroenterol Hepatol 2011; 26 (Suppl 5): 249.

23. Isomura $Y$, Yamaji $Y$, Yamada A, Watanabe $Y$, Suzuki H, Kobayashi $Y$, et al. Irsogladine improves small intestinal injuries in regular users of non-steroidal anti-inflammatory drugs. Gastrointest Endosc. 2014; 80(1): 118-25. doi: 10.1016/j.gie.2013.12.030.

24. Kurishita A, Takai Y, Ueda F, Sakamoto K, Ono T. Post-irradiation protective effect of irsogladine maleate on intestinal crypt stem cells in mice. Strahlenther Onkol. 1992; 168(12): 728-31.

25. Kyoi T, Oka M, Noda K, Ukai Y. Phosphodiesterase inhibition by a gastroprotective agent irsogladine: preferential blockade of cAMP hydrolysis. Life Sci. 2004; 75(15): 1833-42.

26. Kyoi T, Oka M, Noda K, Ukai Y. Irsogladine prevents monochloramineinduced gastric mucosal lesions by improving the decrease in mucosal blood flow due to the disturbance of nitric oxide synthesis in rats. J Pharmacol Sci. 2003; 93(3): 314-20.

27. Kyoi T, Noda K, Oka M, Ukai Y. Irsogladine, an anti-ulcer drug, suppresses superoxide production by inhibiting phosphodiesterase type 4 in human neutrophils. Life Sci. 2004; 76(1): 71-83.

28. Uzzau S, Cappuccinelli P, Fasano A. Expression of Vibrio cholerae zonula occludens toxin and analysis of its subcellular localization. Microb Pathog. 1999; 27(6): 377-85.

29. Sawada N, Murata M, Kikuchi K, Osanai M, Tobioka H, Kojima T, et al. Tight junctions and human diseases. Med Electron Microsc. 2003; 36(3): 147-56.

30. Morita H, Katsuno T, Hoshimoto A, Hatakeyama K, Suzuki Y, Saito Y. Irsogladine, an activator of gap-junctional intercellular communication, suppresses paracellular permeability of human intestinal epithelial cell monolayers through up-regulation of claudin-4. Gastroenterology. 2006; 130 (Suppl 2): A241.

31.Zhang X, Tajima K, Kageyama K, Kyoi T. Irsogladine maleate suppresses indomethacin-induced elevation of proinflammatory cytokines and gastric injury in rats. World J Gastroenterol. 2008; 14(30): 4784-90.

32. Bjarnason I, Williams P, Smethurst P, Peters TJ, Levi AJ. Effect of non-steroidal anti-inflammatory drugs and prostaglandins on the permeability of the human small intestine. Gut. 1986; 27(11): 1292-7.

33. Higuchi K, Umegaki E, Watanabe T, Yoda Y, Morita E, Murano M, et al. Present status and strategy of NSAIDs-induced small bowel injury. J Gastroenterol. 2009; 44(9): 879-88. doi: 10.1007/s00535-009-01022 .

34. Hasleton PS, Carr N, Schofield PF. Vascular changes in radiation bowel disease. Histopathology. 1985; 9(5): 517-34. 